\title{
INTERLOCKING BOARDS AND THE CORPORATE ELITE: A 20-YEAR ANALYSIS OF THE S\&P 500
}

\author{
Kevin Mentzer, Bryant University, kmentzer@bryant.edu \\ Ying Wang, Bentley University, ywang@bentley.edu \\ Dominique Haughton, Bentley University, dhaughton@bentley.edu
}

\begin{abstract}
This work examines the corporate board structure of companies comprising the S\&P 500. The interlocked nature of corporate boards has long been an interest in understanding the social elite within our society and this work continues this examination by covering the most recent 20 years. Using social network analysis tools, we examine the network attributes of the interlocked corporate board network and look at how these measures have changed over the past 20 years. We then compare these networks with a similar randomly generated network to better understand whether these networks are similar to a random network. Using advanced Bayesian analysis we are able to test for statistically significant change over time. We find that the interlocked corporate network continues to exhibit consistency over time. While changes are significant year over year, those changes appear to act as a counter-balance which maintains the network consistency. With the exception of unconnected nodes, the interlocked network is quite similar to a random network. Finally, in support of earlier work, no single type of company maintains a central role in the network over time.
\end{abstract}

Keywords: Interlocking Boards, Social Network Analysis (SNA), Corporate Structure, Corporate Elites

\section{INTRODUCTION}

Mills' book The Power Elite (Mills, 1956) brought forth the notion that there is an 'elite' class of individuals who are responsible for setting the corporate, political, and social agendas in our society. The elites are comprised of corporate leaders including CxO's and corporate board members, as well as those who hold other positions of leadership in social and religious institutions. Mark Mizruchi, in The Fracturing of the American Corporate Elite (Mizruchi, 2013), stated that the corporate elite have been losing power over decades, and the result is a lack of social direction due to the loss of a central message from the elite. One way to analyze this network of elites is through corporate interlocked boards. Two companies are considered interlocked when they share at least one board member. The corporate board meetings offer an opportunity for the elite to share knowledge and ideas which could lead to this centralized message. However an examination of interlocked corporate boards by Davis, Yoo, and Baker (Davis, Yoo, \& Baker, 2001) showed little change from 1982 through 1999. This paper revisits this topic by examining the subsequent 20 year period. Using network analysis, we test whether there is statistically significant change in the level of interlockedness as well as examine the companies most central in these networks to understand whether certain types of companies are better connected than others. Our analysis continues to find little support that these networks are changing significantly, nor do we find that any particular domains (i.e. finance, technology, etc.) have emerged as those most central to these networks. Our findings suggest that the interlocked board network acts, in many ways, similar to a random network. This similarity to randomness lends support to Mizruchi's argument that the elite network lacks a centralized voice when examined through the interlocked corporate board network.

\section{LITERATURE REVIEW}

In 1956 Mills' book The Power Elite (1956) described our society as one that is controlled by a small group of individuals termed the "elite." These elite are in control of not only the corporations, but also politics and society as a whole. This is a singular group whose members serve as CEOs of the major corporations, financiers of the political process which determines who can successfully run for political office, and leaders of our societal institutions such as the churches and other non-profits that provide necessary services to our society. In essence, wherever there is power and money, the persons behind those institutions are all controlled by this elite group of individuals. 


\section{Issues in Information Systems}

Volume 21, Issue 4, pp. 156-167, 2020

One way in which these elite can be identified is through corporate boards of directors. The board of directors is a necessity of all publicly traded companies in the U.S., with a typical board consisting of 10 or more members (Bouwman, 2011), with the average director participating in three boards (E. M. Fich \& Shivdasani, 2006), and the directors of larger firms participating in more boards than those of smaller firms (Bouwman, 2011; Ferris, Jagannathan, \& Pritchard, 2003). Interlocked boards, also called overlapping boards, occur when a "person affiliated with an organization sits on the board of directors of another organization” (Mizruchi, 1996).

Examining the evolutions and characteristics of interlocking boards has been of significant research interest for many decades now. Early research into interlocked boards focused on how information flowed throughout this network (Coleman, 1964, 1988). Topics such as CEO compensation and turnover (E. Fich \& White, 2003; Hallock, 1997), firm earnings (Mindzak, 2013), risk of takeover (Stuart \& Yim, 2010), and overall weak corporate governance (E. M. Fich \& Shivdasani, 2012) all question whether high levels of interlockedness, along with board members serving on too many boards, are leading boards to be ineffective as corporate monitors (Devos, Prevost, \& Puthenpurackal, 2009; E. M. Fich \& Shivdasani, 2012).

Others are interested in studying the relationship external factors have on boards and whether board composition successfully decreases these risks. Understanding the impact board characteristics have in a firm's ability to respond to environmental discontinuities is critical to know since these political, social, technological, or economic changes present significant challenges to firms (Hoppmann, Naegele, \& Girod, 2019; Keck \& Tushman, 1993; Meyer, Brooks, \& Goes, 1990). Hoppmann (Hoppmann et al., 2019) finds that change in board composition conflicts with board member self-interest which in turn can lead to ineffective corporate governance.

There are conflicting views of whether our society benefits or not from having an elite class. On one hand, there are vocal public groups, such as Occupy Wall Street (OWS), who argue against having an elite group of individuals in control of our society. They argue that this elite group (termed the 1\%) has driven our society to extreme division in wealth distribution, resulting in severe economic inequality between the $1 \%$ and the $99 \%$. On the other hand some, including Mizruchi (2013), argue that much of the dysfunction we see in today's society is a result of a weakening elite class. He argues that having a cohesive group responsible for shaping society benefits society as a whole and since World War II, this elite group has been fracturing and no longer retains that singular voice.

While significant focus has been placed on the dyadic relationships created as a result of an interlocked board, other research has examined the structure of the network itself (Barabási, 2003; Chhaochharia \& Grinstein, 2007) and how changes to the structure impact the exchange of ideas (Davis et al., 2001). Recognizing that information flows throughout the network makes it clear that in order to understand this information flow one needs to look beyond the interlocked relationship of two firms and instead understand how those two firms operate within the larger network.

Davis et al (Davis et al., 2001) studied the changes in interlocked corporate boards for the "largest US corporations" including the S\&P 500, from 1982 to 1999. They found that no particular type of firm maintained a central role in the interlocked network and that the level of connectivity was surprisingly consistent. Lluch and Salvaj (2014) examine Argentinian firms over an 80 year period. They find that the number of isolated firms increased from $23 \%$ in 1937 to $60 \%$ in 2000 while the percentage of interlockers as board members decreased from $18.6 \%$ to $8.5 \%$ over that same period. Maman (1999) looked at interlocking ties of Israeli business groups over the period of 1974-1987 and found that the level of interlocking remained relatively constant over this period. It is interesting to note that the period of most change in the Lluch and Salvaj study was between the years 1970 and 1990 which is close to the same period in the Maman study where very little change was observed.

\section{RESEARCH METHODOLOGY}

Twenty years after Davis et al examined the level of interlocked boards for the largest US companies, our research centered upon the following research question:

$\mathrm{RQ}_{1}$ : Has the level of interlockedness of corporate boards changed significantly over the past 20 years? 


\section{Issues in Information Systems}

Volume 21, Issue 4, pp. 156-167, 2020

To test this research question, we analyze the board of director composition of each company comprising the S\&P 500 index over the past 20 years. Using social network analysis (SNA), we treat each year in our study as a network of companies with the ties between those companies representing a shared board member. In order to understand the characteristics of the network we compare key statistics from those networks with each other. Our analysis spanned a period 20 years (2000 through 2019) and in order to effectively compare key network characteristics from year to year, we included only those companies that were in the S\&P500 during the entire period of our analysis $(n=228)$. In our comparison of the different networks we will focus on network density. Network density is calculated as the number of ties in the network divided by the number of possible ties where the number of possible ties is n(n-1) / 2 . This density becomes our measure for the level of interlockedness within the network for that year.

While we expect changes in density year over year, testing for statistical significance in these networks is difficult due to the challenge that links frequently carry over from one time period to the next and therefore tests that rely on independent observations cannot be employed. To overcome this challenge, we employ a Bayesian analysis to test for significance in network change over time. This approach allows for links to not be independent. Using the $\mathrm{P}_{1}$ model (Swartz, Gill, \& Muthukumarana, 2015; Wong, 1987) and extended by Mentzer, et al (Mentzer, Haughton, Dudouet, Latouche, \& Rossi, 2015) we are able to test for statistical significance in the changes of the social network. With this approach we are able to perform pair-wise comparisons between subsequent periods in our study to test whether changes in density are significant. Using these pairwise comparisons we are then able to see if there is an overall trend towards, or away from, a more interlocked network.

\section{ANALYSIS AND RESULTS}

We begin by comparing the visualized social network of interlocked companies from 2000 (Figure 1) and 2019 (Figure 2). Our visualization uses the ForceAtlas2 algorithm (Jacomy, Venturini, Heymann, \& Bastian, 2014) which is a forcedirected layout providing an easy to understand visualization. Each circle (i.e. node) represents a company in the S\&P 500 while each line (i.e. edge) ties two nodes and represents that the boards of directors of each company share at least one board member. The nodes are sized based on the number of connections while the edges are sized (width) based on the number of shared connections with more shared members represented as a wider width of the edge. We perform community detection to identify communities who share similar board members and those are represented through the coloring of the nodes and edges. Visually, the starting and ending networks look quite similar with the exception of the number of nodes floating around the edge, which has seen a significant decrease in numbers from 2000 to 2019. These free-floating nodes represent companies that have no shared board members with any other company in the network for that year.

We report the key network measures for each year in Table 1. The number of connections (average degree) between companies range from 3.570 to a high of 4.079 indicating that most companies are interlocked, i.e. sharing at least one board member, with $3 \frac{1}{1} 2$ to 4 companies during this time. Since our network is weighted based on the number of shared board members, the weighted average degree represents how many individuals are shared between companies. So, while companies on average have 3.809 connections to other companies, they share 8.165 individual board members with those companies. This means that on average companies share 2.14 board members with companies they have a connection to. 


\section{Issues in Information Systems}

Volume 21, Issue 4, pp. 156-167, 2020

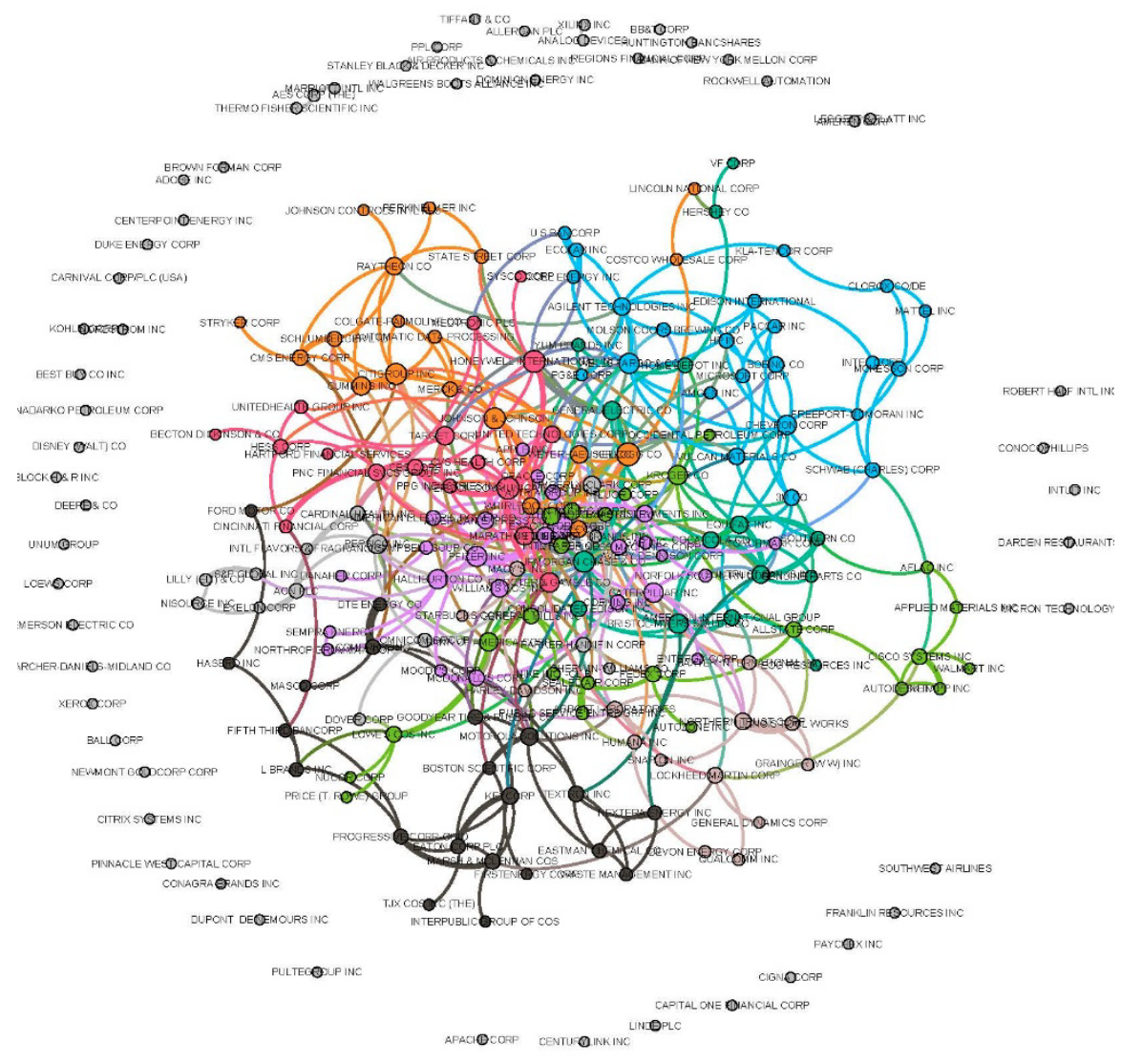

Figure 1. Interlocked Network 2000 


\section{Issues in Information Systems}

Volume 21, Issue 4, pp. 156-167, 2020

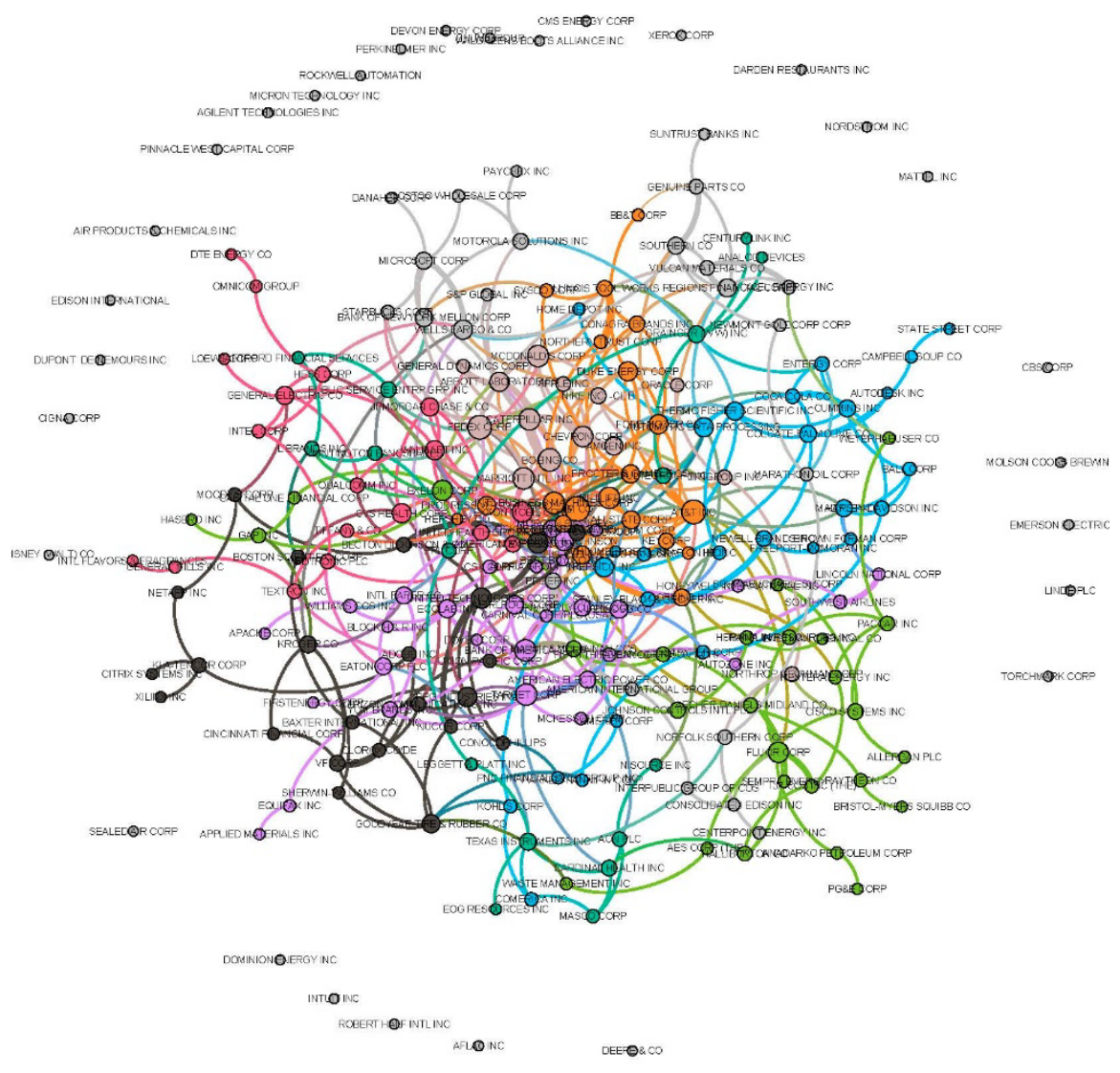

Figure 1. Interlocked Network 2019 


\section{Issues in Information Systems \\ Volume 21, Issue 4, pp. 156-167, 2020}

The average path length represents the average of the shortest path between all pairs of nodes. This shows us how many connections are needed to get from one company to another through the shared board members. The average path length of 3.793 suggests that most companies are fairly well connected to others and the spread of information would be relatively easy in this network. The network diameter is the longest of these shortest paths. In other words, it shows us how many connections are needed to hop between the two most distant nodes in the graph. The average network diameter of 8.95 tells us that the most distant nodes, not accounting for unconnected nodes, is approximately 9 companies away from each other. Both of these measures have remained relatively consistent over the 20-year period.

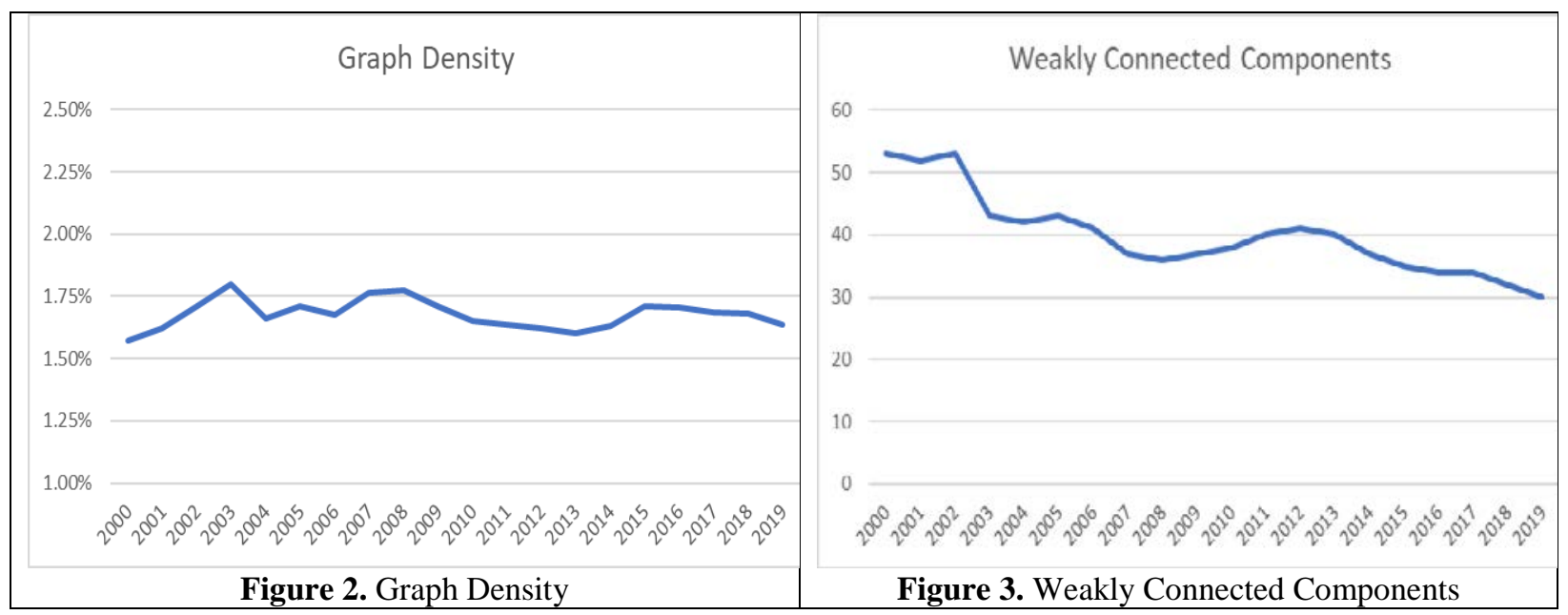

As seen in Figure 3, graph density, after rising slightly at the beginning of our period of study, remained fairly consistent across the entire period. This suggests no overall trend towards or away from the propensity to interlock. The average graph density of $1.68 \%$ means that on average, over the 20 -year period, each company is connected to $1.68 \%$ of the other companies in this network.

Next we turn to the weakly connected components. To be classified as a weakly connected component a company would either share no connection with any other nodes in the network or share very few connections and those connections would be to companies also not connected to the larger community. One trend that does emerge in our study is the decrease in the number of companies not sharing a board member with at least one other company in the study (see Figure 4). Of our 228 companies in our analysis 53 (23.25\%) are classified as weakly connected in 2000 while only 30 (13.16\%) are weakly connected in 2019.

To better understand our networks, we compare them to a randomly generated network using the same number of nodes as well as the average number of connections from our networks (see Figure 5). The random network was generated using the same number of nodes and frequency of connections between those nodes. Figure 5 shows the visualization of the random network. What we find is that our network is quite similar to a random network with the exception of weakly connected components. Both the set of interlocked networks and the random network exhibit similar number of size of communities. However, unlike the random network, the interlocked networks exhibit a large number of weakly connected companies. As can be seen in Table 1 , the number of weakly connected companies ranged from 53 in 2000 to 30 in 2019 while our random network had just 3 weakly connected components. 


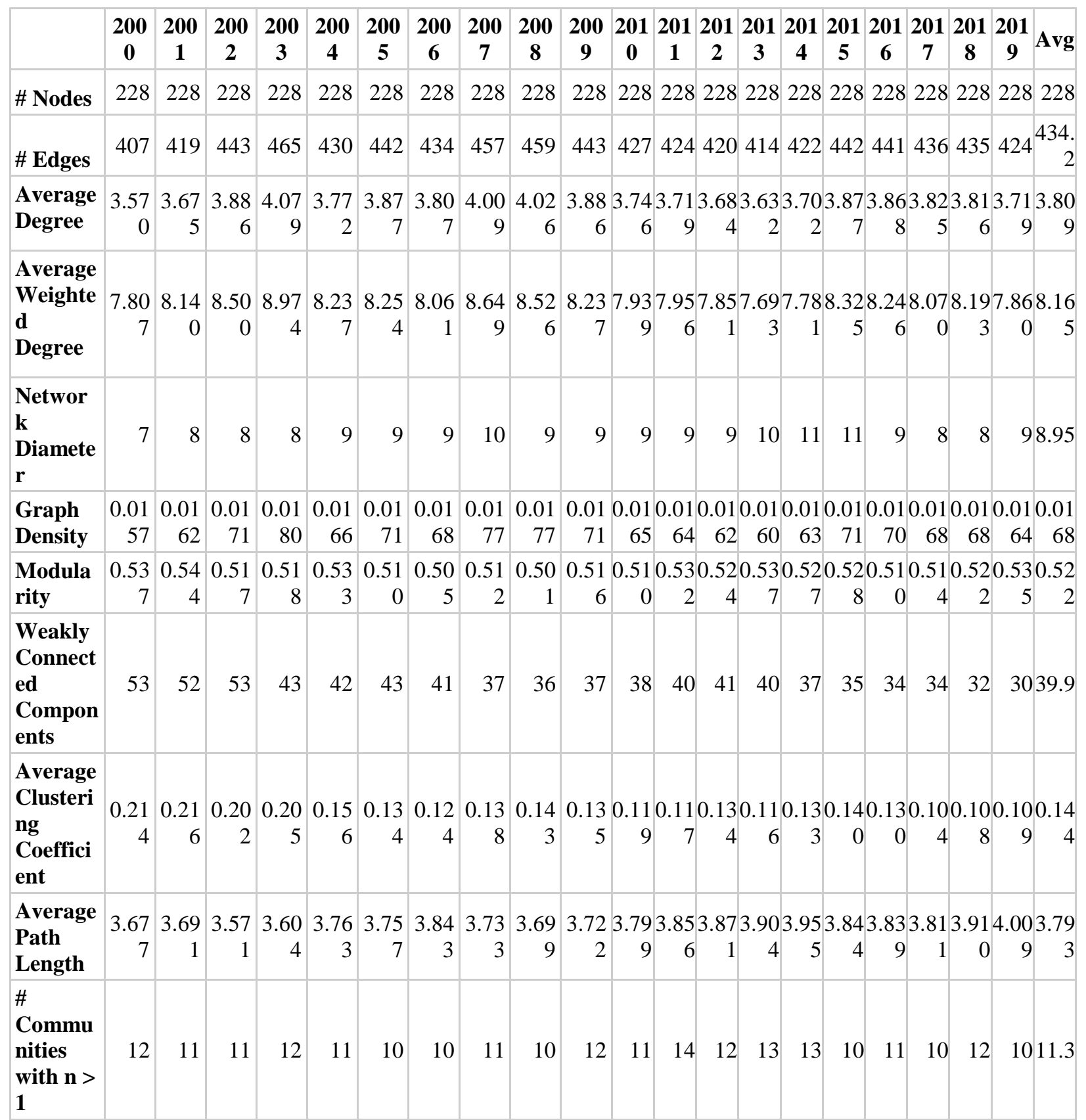

Table 1. Key Network Level Measures of S\&P 500 Network 


\section{Issues in Information Systems}

Volume 21, Issue 4, pp. 156-167, 2020

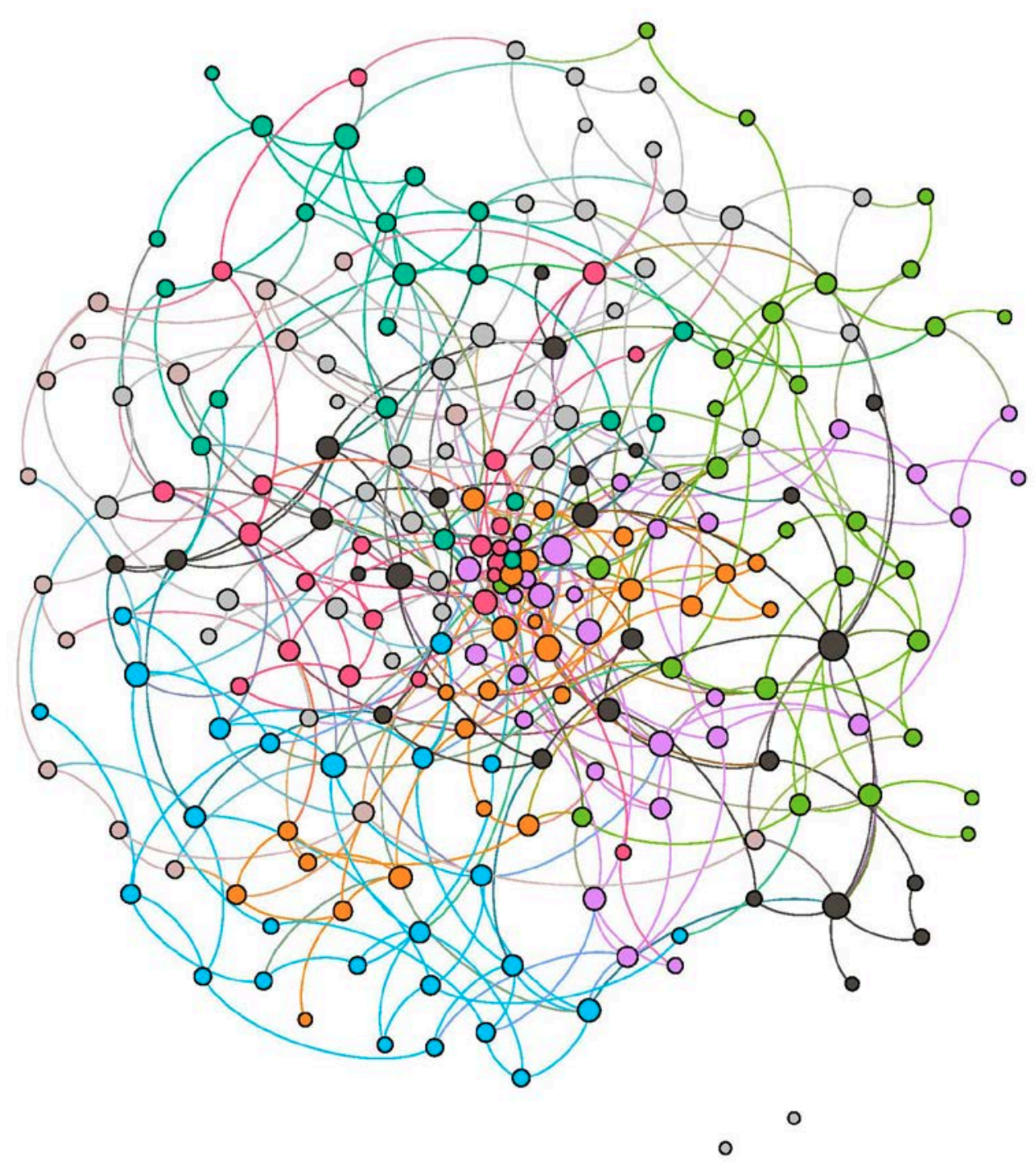

Figure 4. Random Network

Using the Bayesian $\mathrm{P}_{1}$ model as extended by Mentzer et al (Mentzer et al., 2015) we investigate whether the trends in Figures 3 and 4 are confirmed through an examination of the posterior distribution of the difference in cohesiveness between each pair of years in our study beginning with 2000 and 2001, and then ending with a comparison of 2018 and 2019. In other words, by looking at the connections between each company and comparing those connections with the subsequent year, we can test whether the network change was statistically significant. Table 2 presents posterior descriptive statistics for the first pairwise years comparison (2000 - 2001). 


\begin{tabular}{|l|l|l|l|l|l|l|}
\hline & Mean & Std Dev & MC Error & $2.5 \%$ Value & Median & $97.5 \%$ Value \\
\hline Diff & -0.5023 & 0.01781 & 0.001822 & -0.5279 & -0.5049 & -0.4595 \\
\hline Rho & 0.9169 & 0.0329 & 0.000 & 0.837 & 0.923 & 0.964 \\
\hline Sigma[1,1] & 0.9185 & 0.2629 & 0.002 & 0.527 & 0.878 & 1.456 \\
\hline Sigma[1,2] & 0.8935 & 0.2585 & 0.002 & 0.508 & 0.854 & 1.508 \\
\hline Sigma[2,1] & 0.8935 & 0.2585 & 0.002 & 0.508 & 0.854 & 1.508 \\
\hline Sigma[2,2] & 1.0360 & 0.3050 & 0.003 & 0.585 & 0.987 & 1.763 \\
\hline Theta[1] & 2.3750 & 0.2932 & 0.009 & 2.974 & -2.369 & 1.807 \\
\hline Theta[2] & 2.4530 & 0.3209 & 0.010 & 3.122 & -2.446 & 1.834 \\
\hline
\end{tabular}

Table 2. Posterior Statistics for the first Pairwise Comparison (2000-2001)

The posterior mean of the difference between 2000 and 2001 is - 0.5023 , with a $2.5 \%$ - 97.5\% credible interval of ($0.5279,-0.4595)$. The negative value of the posterior mean of the difference indicates an increase in the cohesiveness of the network between 2000 and 2001. Since the 95\% credible interval is entirely in negative territory, this demonstrates that this increase in density is statistically significant. Had the credible interval included 0 then we could not make a claim in either direction. Figure 6 shows the posterior mean of the difference between successive year pairs along with the credible interval.

While there is statistically significant change from one year to the next, this chart is telling us that there is no clear trend over the 20-year period either towards or away from cohesiveness.

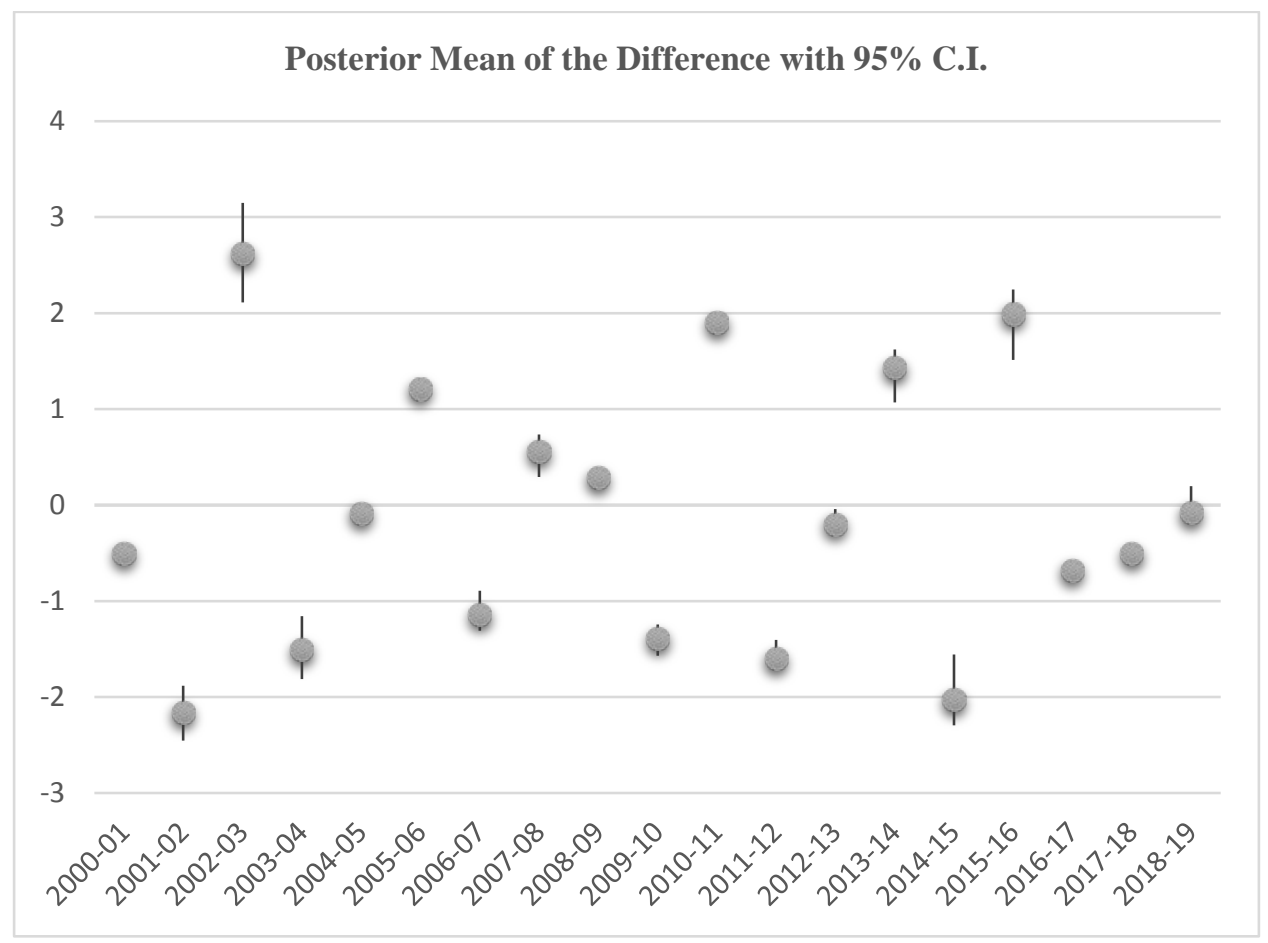

Figure 5. Posterior Mean of the Difference

Finally, we look at the companies in terms of how central they are in the network. As explained in Davis et al (Davis et al., 2001), over the years there have been two opposing views regarding the structure of the elite network of board members. On the one hand is the argument that financial institutions are critically important and therefore would play a central role, while on the other hand others argue that this network is unplanned and therefore connections are simply coincidence. 


\section{Issues in Information Systems \\ Volume 21, Issue 4, pp. 156-167, 2020}

It is important to note that our time period begins near the peak of the dot com bubble, followed by the dot-com burst, which fed into the financial crises of 2007-08. To test this structure we look at the ten most central firms, using the eigenvector measure of centrality, in the network for 2000, 2009, and 2019 (see Table 3). In comparing the most central firms over the 20 year period it is important to note a couple of key findings. First, no single vertical domain dominates any of the lists. For example, while there are financial institutions in the lists, they don't make up a majority of companies. Second, no single company has maintained a central position over the 20 year period. In other words, there isn't a single company that appears in all three lists. In fact, there are only three companies that show up in the subsequent top ten list (Proctor \& Gamble, McDonalds, and Caterpillar), none of which are financial firms.

\begin{tabular}{|l|l|l|}
\hline 2000 & 2009 & 2019 \\
\hline Exxon Mobil Corp (17) & McDonalds Corp (13) & Boeing Co (11) \\
\hline Verizon Communications Inc (13) & Caterpillar Inc (12) & 3M Co (13) \\
\hline JPMorgan Chase \& Co (12) & United Technologies Corp (13) & Fedex Corp (12) \\
\hline Kellogg Co (14) & Eli Lilly \& Co (12) & Caterpillar Inc (10) \\
\hline Johnson \& Johnson (12) & S\&P Global Inc (8) & Marriott Intl Inc (10) \\
\hline Pfizer Inc (11) & Marathon Oil Corp (10) & McDonald's Corp (10) \\
\hline Honeywell International Inc (13) & Proctor \& Gamble Co (9) & IBM Corp (10) \\
\hline Metlife Inc (7) & Citigroup Inc (11) & AT\&T Inc (12) \\
\hline Proctor \& Gamble Co (10) & Northern Trust Corp (10) & Chevron Corp (9) \\
\hline Halliburton Co (10) & Wells Fargo \& Co (11) & Exxon Mobil Corp (9) \\
\hline
\end{tabular}

Table 3. Ten Most Central Firms 2000-2019

\section{CONCLUSIONS}

This work examined interlocked corporate boards of companies making up the S\&P 500. Using social network analysis, we found no significant general trend towards, or away from, a more cohesive network suggesting that the interconnectedness has remained fairly consistent over this period of time. While year over year changes are statistically significant based on our Bayesian analysis, movement in subsequent years appear to counter-balance any changes negating any overall trend. These finding are consistent in the overall level of interconnectedness as Davis et al (Davis et al., 2001) while extending the period examined to encompass an additional 20-year period.

When compared to a randomly generated social network consisting of the same number of nodes, the two networks were remarkably similar with the one exception being the number of companies not connected to their peers. This finding suggests that some companies may be making a concerted effort to reduce influence caused by interlocked boards by choosing board members based on whether they lack a connection to other companies in the S\&P 500 . However, the number of companies that are weakly connected has decreased considerably over the past 20 years. This finding suggests that while earlier concerns regarding negative influence of interlocked boards may have resulted in companies making the choice of choosing board members who wouldn't create an interlock, this influence seems to have dramatically decreased over time.

Contrary to the long-held assumption that financial firms, because of their financial power, hold central roles in corporate networks, when we evaluated the most central firms across the past twenty year, there does not appear to be any dominant vertical market. In addition, companies that play a central role in the network don't appear to maintain this position over time. These findings lend additional support that this network operates similar to a random network.

\section{LIMITATIONS}

Because of the longitudinal nature of this study we had to limit the number of companies evaluated to those who were in the network during the entire 20 year period. While this was necessary for cross-period comparisons, individual year level metrics could be obtained by looking at the entire 500 companies comprising the S\&P 500 for that year. While we find that the level of interlockedness has remined consistent, we cannot explain the surprising result in the strong increase away from isolation (i.e. the decrease in the number of companies with no interlocked member) which represents an area for future study. 


\section{REFERENCES}

Barabási, A.-L. (2003). Linked: The new science of networks: American Association of Physics Teachers.

Bouwman, C. H. (2011). Overlapping boards of directors: Causes and consequences for corporate governance. Financial Contagion: The Viral Threat to the Wealth of Nations, Wiley \& Sons Publishers.

Chhaochharia, V., \& Grinstein, Y. (2007). The changing structure of US corporate boards: 1997-2003. Corporate Governance: An International Review, 15(6), 1215-1223.

Coleman, J. S. (1964). Introduction to mathematical sociology. Introduction to mathematical sociology.

Coleman, J. S. (1988). Social capital in the creation of human capital. American journal of sociology, 94, S95-S120.

Davis, G., Yoo, M., \& Baker, W. (2001). The Small World of the Corporate Elite, preprint, University of Michigan Business School. Ann Arbor, MI.

Devos, E., Prevost, A., \& Puthenpurackal, J. (2009). Are interlocked directors effective monitors? Financial Management, 38(4), 861-887.

Ferris, S. P., Jagannathan, M., \& Pritchard, A. C. (2003). Too busy to mind the business? Monitoring by directors with multiple board appointments. The Journal of Finance, 58(3), 1087-1112.

Fich, E., \& White, L. J. (2003). CEO compensation and turnover: The effects of mutually interlocked boards. Wake Forest L. Rev., 38, 935.

Fich, E. M., \& Shivdasani, A. (2006). Are busy boards effective monitors? The Journal of Finance, 61(2), 689-724.

Fich, E. M., \& Shivdasani, A. (2012). Are busy boards effective monitors? Corporate Governance (pp. 221-258): Springer.

Hallock, K. F. (1997). Reciprocally interlocking boards of directors and executive compensation. Journal of financial and Quantitative Analysis, 331-344.

Hoppmann, J., Naegele, F., \& Girod, B. (2019). Boards as a source of inertia: Examining the internal challenges and dynamics of boards of directors in times of environmental discontinuities. Academy of management journal, 62(2), 437-468.

Jacomy, M., Venturini, T., Heymann, S., \& Bastian, M. (2014). ForceAtlas2, a continuous graph layout algorithm for handy network visualization designed for the Gephi software. PloS one, 9(6).

Keck, S. L., \& Tushman, M. L. (1993). Environmental and organizational context and executive team structure. Academy of management journal, 36(6), 1314-1344.

Lluch, A., \& Salvaj, E. (2014). Longitudinal Study of Interlocking Directorates in Argentina and. The Power of Corporate Networks: A Comparative and Historical Perspective, 257.

Maman, D. (1999). Research Note: interlocking Ties within business groups in Israel—A longitudinal analysis, 19741987. Organization Studies, 20(2), 323-339. 
Mentzer, K., Haughton, D., Dudouet, F.-X., Latouche, P., \& Rossi, F. (2015). Is the corporate elite disintegrating? Interlock boards and the Mizruchi hypothesis. Paper presented at the 2015 IEEE/ACM International Conference on Advances in Social Networks Analysis and Mining (ASONAM).

Meyer, A. D., Brooks, G. R., \& Goes, J. B. (1990). Environmental jolts and industry revolutions: Organizational responses to discontinuous change. Strategic Management Journal, 93-110.

Mills, C. W. (1956). The power elite: Oxford University Press.

Mindzak, J. (2013). Interlocked boards of directors, voluntary disclosures and earnings quality. Voluntary Disclosures and Earnings Quality (February 2013).

Mizruchi, M. S. (1996). What do interlocks do? An analysis, critique, and assessment of research on interlocking directorates. Annual review of sociology, 271-298.

Mizruchi, M. S. (2013). The fracturing of the American corporate elite: Harvard University Press.

Stuart, T. E., \& Yim, S. (2010). Board interlocks and the propensity to be targeted in private equity transactions. Journal of Financial Economics, 97(1), 174-189.

Swartz, T. B., Gill, P. S., \& Muthukumarana, S. (2015). A Bayesian approach for the analysis of triadic data in cognitive social structures. Journal of the Royal Statistical Society: Series C (Applied Statistics), 64(4), 593610.

Wong, G. Y. (1987). Bayesian models for directed graphs. Journal of the American Statistical Association, 82(397), 140-148. 